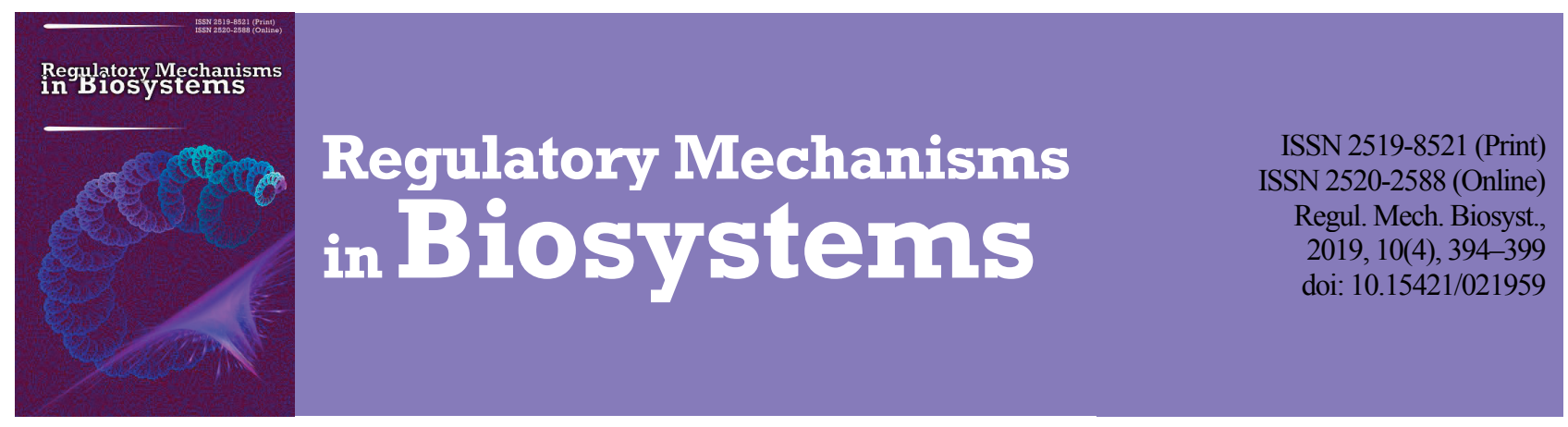

\title{
Microscopic changes in the digestive organs of domestic canaries poisoned with canthaxanthin
}

\author{
J. K. Serdioucov*, S. M. Zabudskyi*, O. V. Kruchynenko**, S. M. Mykhailiutenko** \\ *National University of Life and Environmental Sciences of Ukraine, Kyiv, Ukraine \\ **Poltava State Agrarian Academy, Poltava, Ukraine
}

Article info

Received 01.10.2019

Received in revised form 27.10.2019

Accepted 29.10.2019

Serdioucov, J. K., Zabudskyi, S. M., Kruchynenko, O. V., \& Mykhailiutenko, S. M. (2019). Microscopic changes in the digestive organs of domestic canaries poisoned with canthaxanthin. Regulatory Mechanisms in Biosystems, 10(4), 394-399. doi:10.15421/021959

National University of Life and Environmental Sciences of Ukraine, Heroiv Oboronyi st. 15/3, Kyiv, 03041, Ukraine. Tel.: +38-066-333-07-36. E-mail:yargog80@ukr.net

Intoxication of canaries with canthaxanthin has been recorded more and more often since the late 1990s. This problem is related to active use of this substance for changing or increasing the colouration of this species of bird. For determining morphological changes during canthaxanthin toxicosis, we formed one control and three experimental groups of domestic canaries, which were given canthaxanthin in different doses. The material for microscopic surveys was isolated from the digestive organs of the examined birds; from this material, histological sections were prepared and stained with hematoxylin and eosin. According to the results of microscopic analysis, we determined that the intoxication of the organism of canaries with canthaxanthin causes a certain complex of changes at the tissue level. We found that canthaxanthin intoxication leads to chronic pathological processes in the digestive organs, both the digestive canal and digestive glands (pancreas, liver). In the organs of the digestive tract (glandular stomach or proventriculus, muscular stomach or gizzard, and the intestine) we found chronic catarrhal inflammation, and also proliPoltava State Agrarian Academy, Scovorody st., 1/3, Poltava, 36003, Ukraine. Tel.: +38-099-062-64-96. E-mail:

oleg.kruchynenko@pdaa.edu.ua ferative processes - cellular infiltration of the stroma, overgrowth of the connective tissue. In some cases we also found distrophic processes such as keratinization of the epithelium of the mucous membrane of the glandular stomach. In the pancreas, except for edema of the stroma, no pathological processes were observed. In the liver, we found different types of dystrophy - protein (granular, hydropic) and fatty (infiltrational). With introduction of the highest doses of canthaxanthin used in the experiment, we determined a tendency towards exacerbation of pathological processes, because, apart from the already mentioned changes, we recorded manifestations of alteration (necrotic processes, disorders in blood circulation). Therefore, we proved that irrational use of canthaxanthin in canary-keeping is a factor that can negatively influence the health of these animals. Using the data we obtained, use of canthaxanthin in the diet of canaries can be correlated with their diet, thus avoiding risk of bird diseases. There is scope for further studies on the impact of canthaxanthin on other organs and the systems of the organs at microscopic level, as well as conducting biochemical and morphological analyses of blood, which would allow the creation of a new complete clinical-anatomical description of this pathology.

Keywords: carotenoids; Serinus canaria domestica; histological changes; digestive tract; pancreas; liver.

\section{Introduction}

The food additive canthaxanthin E161g is an orange colouring (EFSA, 2010). It belongs to the class of carotenoids (Delia, 2015; Gerald et al., 2017). The origin of canthaxanthin is natural, it was first found in edible mushrooms (Johnson, 2019). Furthermore, E161g is present in some bacteria, organisms of carp, Mugil, various crustaceans, in green algae (Amaya et al., 2015; Esatbeyoglu, et al., 2016; Oehlenschläger et al., 2016). The additive is sensitive to temperature differences and light. According to the manual, the food colouring should be kept in a dark place at a cold temperature, in an atmosphere of inert gas.

Familiar names of this colouring are canthaxanthin, food orange 8, canthaxanthin (Bendich et al., 2006). Usually, E161g is a crystalline powder or crystals of intense violet colour (Surai, 2012; Alonso-Alvarez et al., 2018). In solution it obtains tones ranging from orange to red. Canthxanthin is well soluble in chloroform, average level of solubility can be achieved by using plant oils. Powder E161g does not dissolve in ethanol and water (EFSA, 2010; El-Agamey et al., 2004). It is considered safe for life and health of humans.

In canary-keeping the colouring is used for maintaining or intensifying red colour of the feathers of canaries in dose of $5 \mathrm{~g}$ per $0.5 \mathrm{~kg}$ of soft feed or per $0.5 \mathrm{~L}$ of water. It is given to adult birds from the beginning of moult to its end, and during the breeding period, to the young from hatching till the end of the juvenile moult (Koch et al., 2015; EFSA, 2014). With irrational use of canthaxanthin, domestic canaries begin to suffer from shortness of breath, short periodic moulting, resulting in the condition of the birds falling below international standards; birds look exhausted; their reproductive abilities are impaired (Sujak, 2009; Judkins, 2018). However, intoxication of canaries with canthaxanthin is quite rarely mentioned in the literature, even in modern foreign journals on bird diseases (Doneley, 2016).

Most species of domestic birds are susceptible to different toxins of animal, plant and chemical origin. High sensitivity of birds is first of all related to their small body sizes, reactivity and metabolism. A bird can become poisoned during free movement in a room, having access to salt, medicines and other substances (Pollock et al., 2016). Almost all species of birds have no instinct against consuming toxic substances, therefore their intoxication is observed quite often. Over the recent years new studies determined a certain extent of sensitivity in birds. It was found that bitter salts in minimum amount can be included in the diet, while high doses slow the consumption of feed (Schmidt, 2015). Not only fodders which contain poisonous substances are dangerous, but 
also fodders of poor quality with toxins of different mushrooms, bacteria, poisonous plants (Bendich et al., 2006). Intoxications with chemical substances occur as a result of ingesting grains treated with herbicides, fertilizers, parts of gypsum, and also salt and sodium pyrosulfite. There have been cases of poisoning with carbon oxide (Schmidt, 2015) and paint which contained salts of heavy metals, particularly zinc. Some species of birds, such as canaries, chaffinches and siskins, can peck paint off, which can result in their death. Many disinfecting substances have a strong toxic effect, for example, formaline, chlorinated lime. Insecticides, pesticides cause death to canaries in 1-3 min (Sobhakumari et al., 2018).

During free flying in the room, poisoning can occur from eating parts of plants of the Philodendron genus (Samour, 2015). Scientific studies prove the possibility of intoxication of small birds with nicotine. The clinical picture is characterized by reduction of appetite, depression, weakness and quick death. Some canaries kept in a room with cigarette smoke were observed to have prolapse of the rectum and the oviduct (Doneley, 2016).

Overdosage and prolonged use of medical preparations, for example sulfanilamides, antibiotics, coxidiostatics, can also cause intoxications with lethal outcome. Most often the intoxications are recorded in the presence of toxic substances in the diet of birds. Depending on the dose of toxic substances, intoxications can be acute and chronic (Doneley, 2016).

\section{Materials and methods}

The studies were conducted in 2017-2019 at the Academician G. Kasianenko Department of Anatomy, Histology and Pathomorphology of Animals, National University of Bioresources and Nature Use of Ukraine (Kyiv). All manipulations with animals in the experiment were performed in accordance with the ethical norms of international and Ukrainian laws.

In the experiment we used 20 domestic canaries (Serinus canaria domestica) aged 1.5 years, of average weight, of normal physiological condition. These birds were divided into 4 groups with 5 birds in each, including three females and two males. In the first group the examined canaries were fed with grain mixture and soft fodders with addition of canthaxanthin in the dose of $5 \mathrm{~g}$ per $0.5 \mathrm{~kg}$ of fodder or $0.5 \mathrm{~L}$ of water during 3 months. In the second group, the experimental canaries were fed with grain mixtures and soft fodders with addition of canthaxanthin in the doses of $10 \mathrm{~g}$ per $0.5 \mathrm{~kg}$ of fodder or $0.5 \mathrm{~L}$ of water during 3 months. In the third group, the experimental canaries were given grain mixtures and soft fodders with addition of canthaxanthin in the doses of $20 \mathrm{~g}$ per $0.5 \mathrm{~kg}$ of fodder of $0.5 \mathrm{~L}$ of water over 3 months. In the fourth (control) group, the canaries received grain mixtures and soft fodders without addition of canthaxanthin in the diet.

The animals in the experiment were euthanized, and then subjected to autopsy. For the study, sections of the organs of the digestive system (glandular and muscular stomachs, small and large intestines, pancreas, liver) were selected. The obtained material was fixed in $10 \%$ buffered solution of formalin according to Lilly (1969); submerged in paraffin; $5-10 \mu \mathrm{m}$ histosections were made and stained by hematoxiline Leica and eosine, and analyzed using an optical microscope msq 2,000, performing microphotography.

\section{Results}

We determined some peculiarities of the microscopic changes in the digestive organs during intoxication with canthaxanthin, typical for canaries. Therefore in the histosections, the deep sections of glands from the glandular stomach appeared to be round or oval formations with radial ramified structures. In the muscular stomach, the villi of the mucous membrane protruded with their apical part into the lumen of the organ and their basal part looked like cellular structure. On the outside, the mucous membrane was covered with a thick layer of the cuticle. The cuticle looked like a pale pink homogenous substance and covered the mucous membrane as a uniform layer, and in the basal part it formed long processes located between the villi of the mucous membrane and formed conjunctions with them. In the intestine of all examined preparations, the villi of the mucous membrane were arranged in stair- or fir tree-like structure. Deep sections of the intestinal glands were stained basophilically. Single cellular infiltrates in the muscularis mucosae were observed between the villi and deep sections of the glands. The circular muscular layer of the muscularis was developed better than the longitudinal one. The ceca had the form of small processes. Peculiarities of the structure of the ceca were the insignificant extent of the development of the superficial epithelium and extremely developed lymphoid tissue in the muscularis mucosae and submucosa. The formations looked like small nodes which bordered both the epithelium layer and mucous membrane and consisted of lymphoid cells.

The animals of the first experimental group had enlarged excretory ducts of the deep sections of the glands in the glandular stomach. The lymph nodes were also increased in size (Fig. 1). We observed certain regions where multi-layered flat epithelium keratinized. In such areas the epitheliocytes were dense and close one to another, the colour of such regions was dark-red with raspberry red tone (Fig. 2). In the villi of the mucous membrane of the muscular stomach, we observed cellular infiltration. The cellular infiltrates were also found in large amounts in the entire layer of the muscular layer in the intramuscular connective tissue. The lumina of the glands of the duodenum were enlarged and filled with a large amount of mucus of bright red colour.

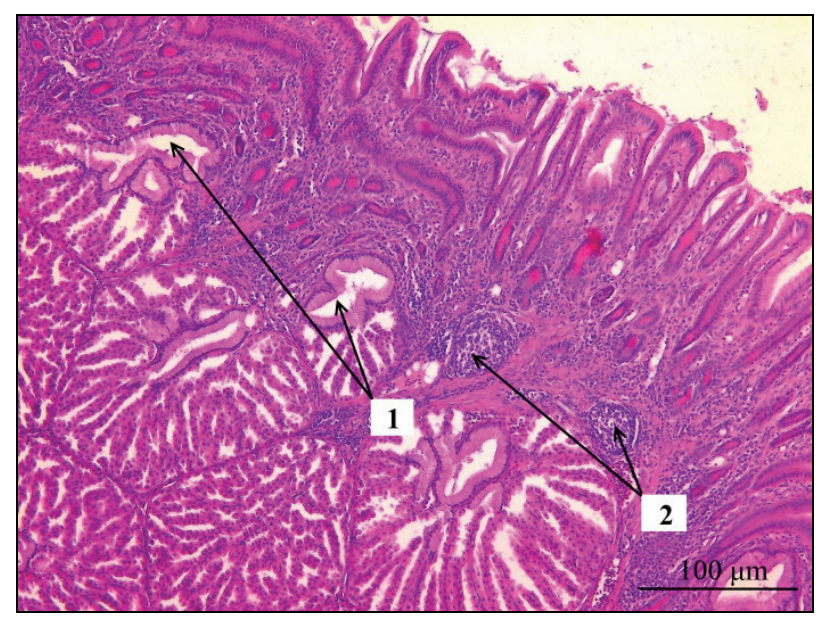

Fig. 1. The glandular stomach of the birds from the first experimental group: widened lumina of the glands (1), enlarged lymph nodes (2); staining with hematoxylin and eosin

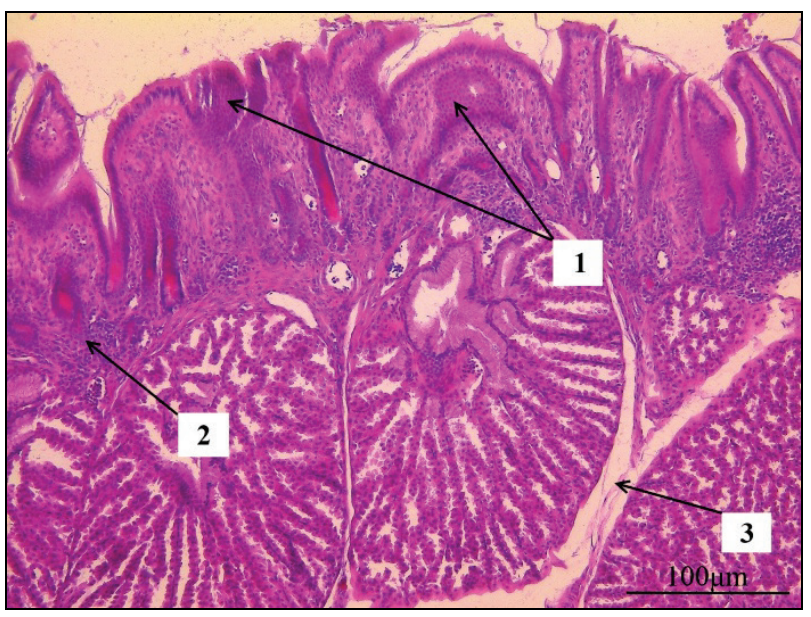

Fig. 2. The glandular stomach of birds of the first experimental group: centres of the keratinization of the mucous membrane (1), cellular infiltration of the mucous membrane (2), edema of the connective tissue of the muscularis mucosae (3); staining with hematoxiline and eosin

In the intestine, compared with the animals of the control group, the number of the goblet cells was increased. In the muscularis, especially in the circular layer, cells were found which had practically transparent cytoplasm and nuclei of oval-prolonged shape. The nuclei in such cells were more strongly stained than in animals of the control group. These 
features can indicate the development of the fatty dystrophy of smooth myocytes. The lumina of the cecum were significantly reduced compared with the animals of the control group, and were completely absent in some preparations (Fig. 3).

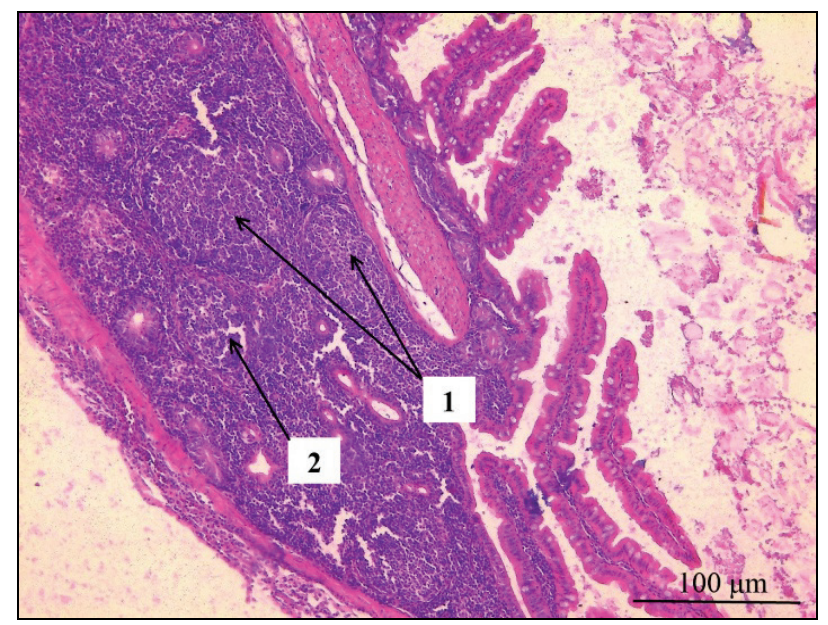

Fig. 3. Cecum of birds of the experimental group: increased lymphoid nodes (1), absence of lumen (2); staining with hematoxiline and eosin

Quite a high number of hepatocytes in the liver was altered. Such hepatocytes had homogenous cytoplasm stained in light pink colour. Nuclei of the cells were on the periphery, near the cellular layer. Nuclei in the cells were stained poorly. Some cells had no nuclei, such cells were bulbs filled with pink content. Such changes indicate development of fatty infiltrational and hydropic dystrophy of hepatocytes (Fig. 4). Interlobular connective tissue in some places was infiltrated with cellular elements, mostly lymphoid cells and heterophyles (Fig. 5). In the pancreas, we observed no changes compared with the animals of the control group.

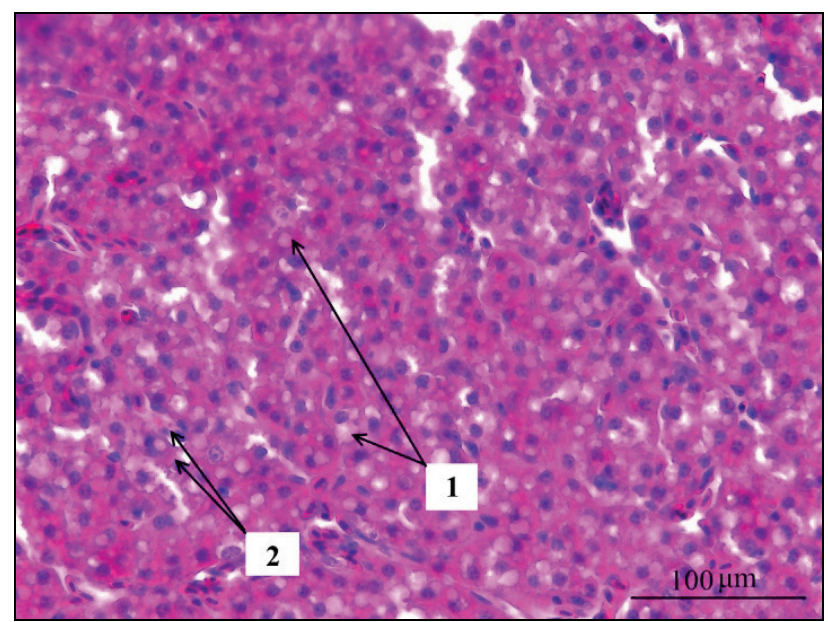

Fig. 4. Liver of birds of the first experimental group:

hepatocytes in the conditions of hydropic (1) and fatty (2) dystrophies; staining with hematoxylin and eosin

The changes in all the examined organs of birds of the second experimental group were similar to those in birds of the first experimental group. In the muscular stomach, we found no cellular formations in the villi bases, which were clearly seen in the birds of the control and other experimental groups.

In the duodenum, the tips of all villi were uniformly eosinophyllically stained, nuclei of the epitheliocytes' nuclei as well as the cellular structures were not found. Often the apices of the villi were separated from them, being present in the lumen of the intestine (Fig. 6). In the ceca, the amount of the goblet cells increased. The rest of the changes were similar to the ones in birds of the first experimental group.

In the glandular stomach of the birds of the third group, the lumina of the glands were enlarged, overfilled with secretion, and the same was 396 observed in the excretory ducts. The vessels of the muscularis mucosae of the mucous membrane were enlarged and congested with blood. In some places we observed destruction of the superficial epithelium. In some preparations, necrosis of the superficial epithelium was noted. In these areas, the folds of the mucous membrane looked like homogenous basophilous substances, in which it was impossible to distinguish the constituents of the mucous membrane's structure. Furthermore, we observed lymphocytic infiltration of the connective tissue of the muscularis mucosae, especially in the places that contacted the basophilous membrane of the epitheliocytes. In some preparations we observed overgrowth of the connective tissue (Fig. 7). The interlayers of connective tissue between deep layers of the glands were largely thickened, with edemas, in some places poorly stained, with collagenic fibers in such places significantly stretched, disrupted. In the centers of overgrowth of the connective tissue, diffusive infiltration with histocytes and cells of the lymphoid row were seen. Deep sections of the glands in such places were enlarged in volume and had hardly any lumina. Some glands were atrophied.

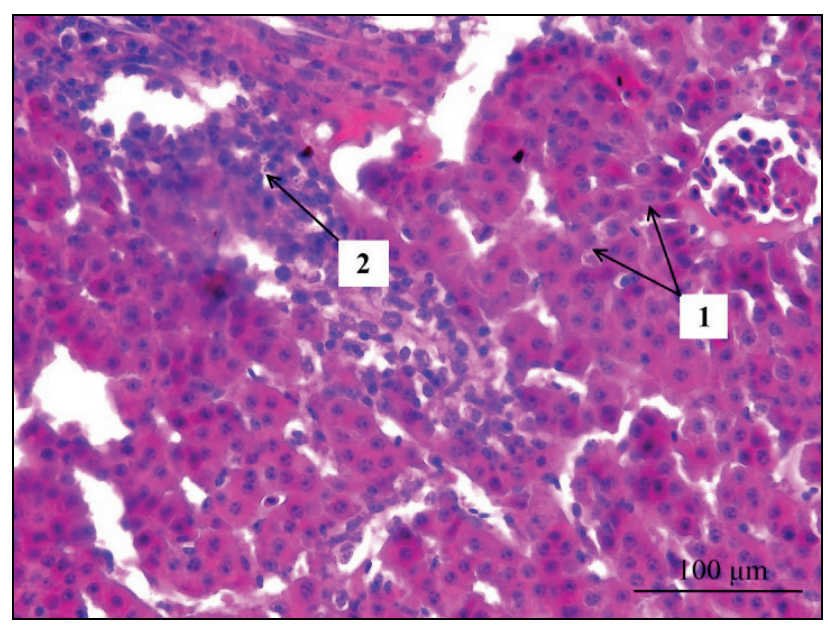

Fig. 5. Liver of birds of the first experimental group: hepatic laminae (1), cellular infiltration of the stroma (2); staining with hematoxylin and eosin

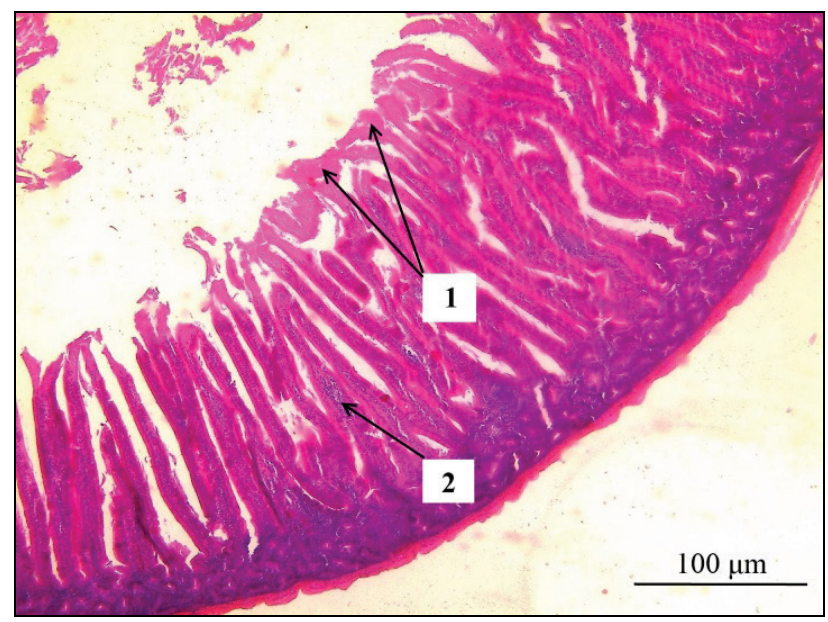

Fig. 6. The duodenum of the birds of the second experimental group: necrosis of the villi ( 1 ); cellular infiltration of the lamina propria of the mucosa (2); staining with hematoxylin and eosin

In some preparations in the duodenum, we observed destruction of the villi. The mucous membrane of the jejunum, especially the villi, was notably infiltrated with the cells of the lymphoid row (Fig. 8). The highest level of infiltration was observed in the area of the muscularis mucosae and the submucosa. Some cells of the infiltrate were observed even in the mucus between the villi.

In the pancreas, the vessels were enlarged and congested with blood. The connective tissue of the stroma formed irregular-shaped "islands" 
of overgrowth (Fig. 9), which penetrated the parenchyma of the gland. In such places, the connective tissue was notably infiltrated with cells of the lymphoid row.

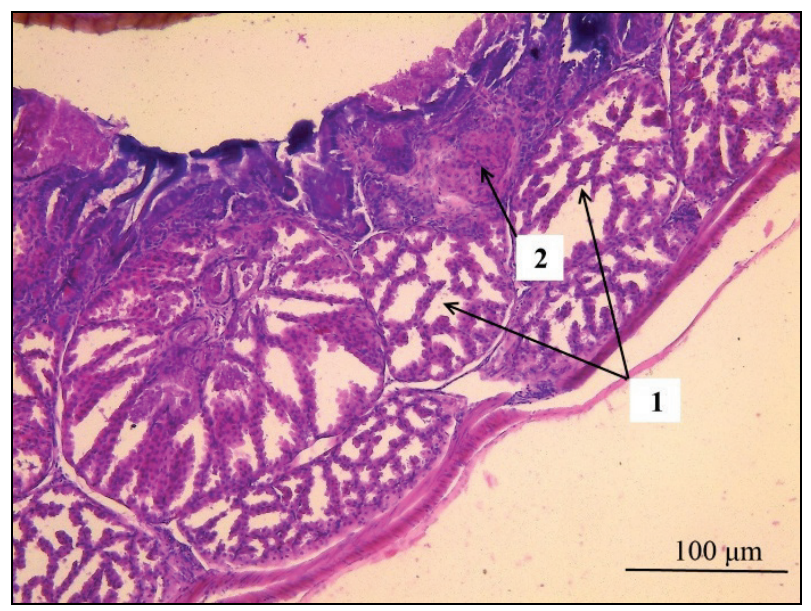

Fig. 7. Glandular stomach of birds of the third experimental group: enlarged lumina of the glands (1), overgrowth of the connective tissue (2); staining with hematoxylin and eosin

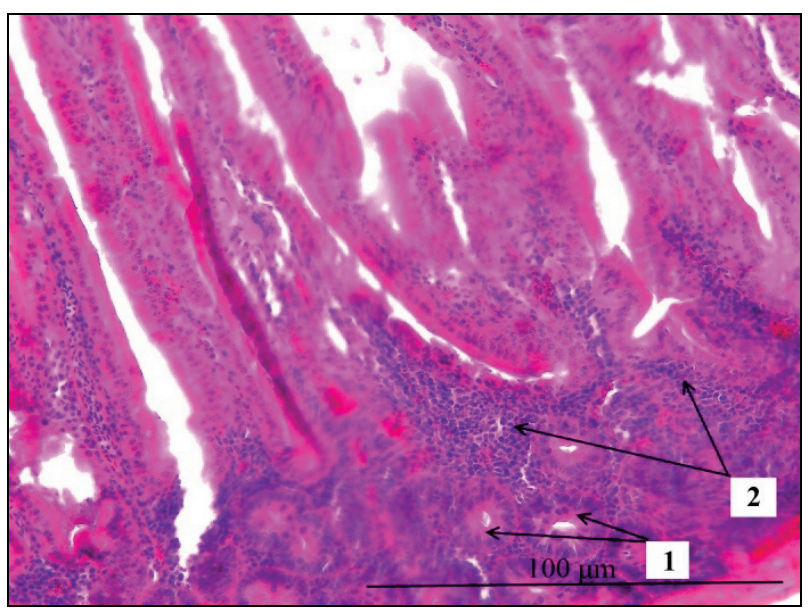

Fig. 8. The duodenum of birds of the third experimental group: intestinal glands (1), inflammatory infiltrate (2); staining with hematoxylin and eosin

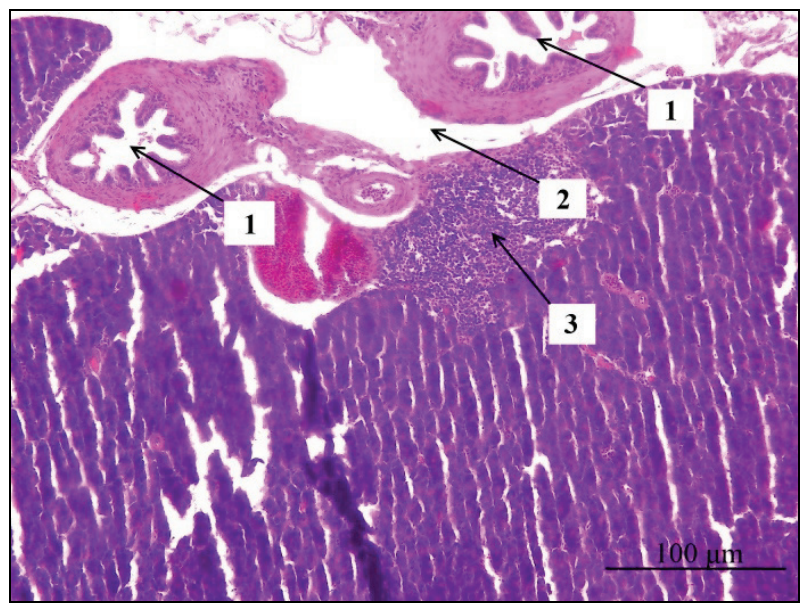

Fig. 9. Pancreas of birds of the third experimental group: the excretory ducts (1), edema of the connective tissue (2) and the centre of its overgrowth (3); staining with hematoxylin and eosin

In the liver some hepatocytes were significantly enlarged and had non-homogenous granular cytoplasm. Nuclei in such cells were poorly stained. Separate hepatocytes had non-stained round areas of cytoplasm. Their nuclei stained well and were in the center of the cell (Fig. 10).
Interlobular connective tissue was infiltrated with cells of the leukocytes, formed by accumulations of round shape. Intra- and interlobular vessels were enlarged and congested with blood.

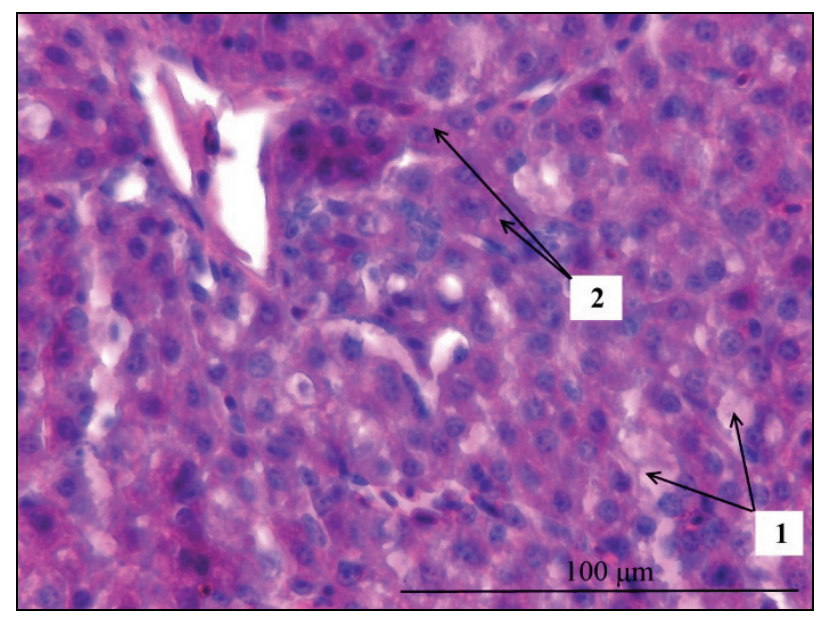

Fig. 10. Liver of the birds of the third experimental group: hepatocytes in the conditions of hydropic (1) and granular (2) dystrophy; staining with hematoxylin and eosin

The rest of the changes were the same as in birds of the first experimental group.

\section{Discussion}

Currently, morphological changes in birds' organs are studied insufficiently, especially for cage birds, during intoxication with different chemical compounds (Walker, 1978; Sobhakumari et al., 2018). Variability of these changes is quite high and depends on many factors, particularly species and individual peculiarities of the organism of birds, intensity of metabolism, nature of the poisoning agent, etc. (Pollock et al., 2016). Direct dependence between chemical composition and dose of poison and pattern of morphological changes is not always found (Sobhakumari et al., 2018). Peculiarities of pathogenesis of most poisonings remain unstudied (Makarov, 2013; Sobhakumari et al., 2018). Furthermore, the small number of sources which contain at least some information on the pathomorphology of any particular intoxication describe productive, and not cage birds (Doneley, 2016; Raftery, 2016).

Intoxication with canthaxanthin is currently a poorly studied pathology (Serdioucov et al., 2014; Serdioucov et al., 2015). This is related to the idea, which has remained common to this day, that canthaxanthin, which is used as a food additive, was absolutely safe for health (Aditya et al., 1985; Abushita et al., 2000; Johnson, 2019). The earlier studies of the authors of this paper have proved that constant use of canthaxanthiin causes certain morphological changes (Serdioucov et al., 2014), as well as changes in biochemical and morphological parameters of the blood (Zabudskyi, 2018; Zabudskyi, 2019).

Recent studies (Serdioucov et al., 2015) have determined that chronic overdosing with canthaxanthin causes severe morphological changes in the organism of domestic canaries. Determination of the mechanisms of the development of these changes reveals peculiarities of toxic effect of this substance on the organism of birds. Because canthaxanthin is introduced into the canaries' organism perorally (with fodder and water), the most characteristic changes should occur particularly in the digestive organs, therefore these organs were chosen as the object of the study.

The results of the study revealed that in general the structure of the digestive organs of the birds of the control group was different from that described for birds in the literature (Bacha et al., 2012; Al-Juboory et al., 2016), though we determined some peculiarities characteristic particularly for canaries. Therefore, we found the following pathological changes in the organs of the digestive system of canaries: in the glandular stomach - chronic catarrhal inflammation, keratinization and necrosis of epithelium, edema and overgrowth of the connective tissue; in the intestine - catarrhal inflammation, necrosis of the villi, hyperplasia of the lymph nodes in the lymphoid tissue of the ceca; in the pancreas - fibro- 
sis; in the liver - granular, fatty infiltrative and hydropic dystrophy of hepatocytes, cellular infiltration of the stroma.

Catarrhal inflammation is characterized by formation of exudates, which consists of serous fluid formed as a result of increase in the penetrability of the vessels of the mucous membrane, a large amount of mucus, and also cells of epithelium of desquamated mucous membranes. With catarrhal inflammation, mucus is produced in large amounts by the cells of superficial epithelium and glandular epithelium as a result of the development in it of mucus dystrophy to different extents (Pattison et al., 2008; Raftery, 2016). Since in our case chronic catarrh was recorded, then the hypersecretion of mucus on the surface of the mucous membrane was not notable, but its presence indicated enlargement of the lumina of deep sections of the stomach glands. A sign of inflammation was also infiltration of the connective tissue of the wall of the stomach by cellular elements. Obviously, inflammation occurs as a response of tissue to weak but constant irritation of the mucous membrane by canthaxanthin that is introduced there with fodder and water.

Necrosis of epithelium of the stomach in birds of the third experimental group can be explained by the toxic cytopathogenic influence of extensive doses of canthaxanthin received by the birds. Poison ruins organelles in cells, leading to complete disorder of metabolic processes and cellular respiration, which ultimately cell death (Saif, 2008; Doneley, 2016).

Edema and overgrowth of the connective tissue of the muscularis mucosae of the glandular stomach occur as a result of the development of inflammatory reaction to the effect of poison. If the edema is a sign of exudation resulting from a reaction of vessels of microcirculating flow, then overgrowth of fibrous connective tissue is a manifestation of the processes of proliferation, which is characteristic for chronic types of inflammation (Schmidt et al., 2015).

In some cases keratinization of the superficial epithelium of the glandular stomach was observed. Keratinization can be considered one of the manifestations of protective reactions responding to irritation of the mucous membrane by canthaxanthin. Moreover, pathological keratinization of mucous membranes in birds is known to occur against the background of vitamin A deficiency (Palmer et al., 2017). Because vitamin A also belongs to the carotenoids' group (Johnson, 2019), one can presume that extensive introduction of canthaxanthin into the organism can cause disorders in the metabolism of this vitamin, leading to such pathology.

The assumption that canthaxanthin is a factor that causes chronic catarrhal inflammation, and in large doses - necrosis, i.e. manifestation of alteration, has been confirmed by the presence of anatomical changes in both the duodenum and jejunum of the experimental birds. And these changes, obviously, occur under impact of extensive doses of canthaxanthin (Sujak, 2009; Doneley, 2016).

Hyperplasia of the lymph nodes, which we recorded in the lymphoid tissue of the ceca, usually occurred during load on the immunity (Pollock et al., 2016). Perhaps, this process is one of the manifestations of protective reaction to irritation by canthaxanthin, as well as products of inflammation, which takes place in other sections of the intestine.

Overgrowth of the connective tissue (fibrosis) is characterized by formation of thickenings and densifications (Raftery, 2016). Apart from the glandular stomach, we observed the same process in the stroma of the pancreas. In this case, overgrowth is conditioned by the development of interstitial inflammatory reaction to toxic impact of canthaxanthin.

In the liver, we found a complex of dystrophic changes: protein (granular, hydropic) and fatty infiltrative dystrophies. Granular dystrophy develops as a result of the action of poison on cytoplasm of hepatocytes, leading to destruction of organelles and other cytoplasmic formations, release of peptides and proteins which form grains of protein origin. Hydropic dystrophy itself is the next, irreversible stage of the development of the dystrophic process and occurs in cells which have been affected by a type of grain dystrophy (Ibragimov, 2007; Antonenko, 2013). Such damages occur during intoxication of any origin (in our case - canthaxanthin) (Sobhakumari et al., 2018). The same factors also condition the development of fatty infiltration of hepatocytes. The mechanism of its development is related to the infiltration of the cytoplasm with lipids introduced from blood, and also, perhaps, with decomposition of lipoprotein complexes of organelles' membranes under the impact of canthaxanthin (Ortiz-Brizuela et al., 2018). In this case, cellular infiltration of the liver stroma is a sign of chronic interstitial inflammatory reaction initiated by the influence of canthaxanthin (Samour, 2015).

In the muscular stomach of the experimental birds, we found no significant morphological changes. This can be related to the non-penetrability of the cuticle of the muscular stomach for particles of canthaxanthin. Therefore, the results we obtained unquestionably prove the chronic toxic effect of canthaxanthin on the digestive organs of domestic canaries.

\section{Conclusions}

In the organism of canaries intoxicated with canthaxanthin, a distinctive complex of microscopic changes develops. In the birds used in the experiment, we found a number of chronic pathological processes in the digestive organs (inflammation, dystrophic changes, overgrowth of connective tissue, cellular infiltration of the stroma), which during introduction of excessive doses of canthaxanthin can be aggravated (necrotic processes, disorders in blood flow). The data we obtained allow correction of use of canthaxanthin in canary-keeping, and thus can help to avoid losses related to reduction of the health condition and death of the birds.

\section{References}

Abushita, A. A., Daood, H. G., \& Biacs, P. A. (2000). Change in carotenoids and antioxidant vitamins in tomato as a function of varietal and technological factors. Journal of Agricultural and Food Chemistry, 48, 2075-2081.

Aditya, K., Gupta, A., Haberman, H., \& Pawlowski, D. (1985). Canthaxanthin. International Journal of Dermatology, 24, 528-532.

Al-Juboory, R., Daoud, H., \& Al-Arajy, A. (2016). Comparative anatomical, histological and histochemical studies of the oesophagus in two different Iraq birds (Columba palumbus and Tyto alba). International Journal of Advanced Research in Biological Sciences, 2(12), 188-199.

Alonso-Alvarez, C., Garcia-de Blas, E., \& Mateo, R. (2018). Dietary canthaxanthin reduces xanthophyll uptake and red coloration in adult red-legged partridges. Journal of Experimental Biology, 221, 1-12.

Amaya, E., \& Nickell, D. (2015). Using feed to enhance the color quality of fish and crustaceans. In: Feed and Feeding Practices in Aquaculture. Woodhead Publishing in Food Science, Technology and Nutrition. Pp. 269-298.

Antonenko, O. M. (2013). Hepatotoxicity: Options for pharmacological correction. Medical Council, 6, 45-51.

Bacha, W., \& Bacha, L. (2012). Color atlas of veterinary histology. 3rd edition. Wiley-Blackwell, West Sussex.

Bendich, A., \& Shapiro, S. (2006). Effect of beta-carotene and canthaxanthin on the immune responses of the rat. The Journal of Nutrition, 2006, 2254-2262.

Delia, B. (2015). Carotenes and xanthophylls as antioxidants. Handbook of Antioxidants for Food Preservation, 2015, 17-50.

Doneley, B. (2016). Avian medicine and surgery in practice: Companion and aviary birds. Second Edition. CRC Press.

EFSA Panel on Additives and Products or Substances used in Animal Feed (FEEDAP). (2014). Scientific opinion on the safety and efficacy of canthaxanthin as a feed additive for poultry and for ornamental birds and ornamental fish. EFSA Journal, 12, 1-24.

EFSA Panel on Food Additives Nutrient Sources added to Food ANS (2010). Scientific opinion on the re-evaluation of canthaxanthin (E 161g) as a food additive. EFSA Journal, 10, 2-10.

El-Agamey, A., Lowe, G., \& McGarvey, D. (2004). Carotenoid radical chemistry and antioxidant/pro-oxidant properties. Archives of Biochemistry and Biophysics, 2004, 37-48.

Esatbeyoglu, T., \& Rimbach, G. (2016). Canthaxanthin: From molecule to function. Molecular Nutrition and Food Research, 2016, 1-17.

Gerald, F., \& James, P. (2017). Vitamin-like factors. In: Combs Jr., G. F., \& McClung, J. P. (Eds.). The vitamins. Fifth Edition. Academic Press. Pp. 453- 498.

Ibragimov, A. A. (2007). Patomorfologiya i diagnostika boleznej pticz [Pathomorphology and diagnostic of avian diseases]. Kolos, Moscow (in Russian).

Johnson, E. (2019). Carotenoids. In: Jonson, J., \& Wallace, T. (Eds.). Whole grains and their bioactives. John Wiley \& Sons Ltd. Pp. 383-391.

Judkins, G. (2018). The canary. Australasian Journal on Ageing, 6, 159-160

Koch, R., McGraw, K., \& Hill, G. (2015). Effects of diet on plumage coloration and pigment deposition in red and yellow domestic canaries. Wilson Journal of Ornithology, 9, 48-66.

Makarov, V. A. (2013). Innovacionnye podkhody v diagnostike i profilaktike boleznej pticz [Innovative approaches in the diagnostic and prevention of avian diseases]. Saratovskij Istochnik, Saratov (in Russian). 
Oehlenschläger, J., \& Ostermeyer, U. (2016). Feed additives for influencing the color of fish and crustaceans. In: Handbook on Natural Pigments in Food and Beverages Industrial. Woodhead Publishing. Pp. 265-281.

Ortiz-Brizuela, E., \& Azamar-Llamas, D. (2018). Granulomatous liver disease. Gaceta Medica de Mexico, 2018, 1-6.

Palmer, A., Darnton-Hill, I., \& West Jr., K. (2017). Vitamin A deficiency. Nutrition and health in a developing world, 2017, 181-234.

Pattison, M., Bradbury, J., McMullin, P., \& Alexander, D. (2008). Poultry Diseases. Saunders Elsevier.

Pollock, C., Klaphake, E., \& Wellehan, J. (2016). Avian medicine: An overview. In: Speer, B. (Ed.). Current therapy in avian medicine and surgery. Saunders. Pp. 1-21.

Raftery, A. (2016). Avian medicine and surgery. In: Speer, B. (Ed.). Current therapy in avian medicine and surgery.

Saif, Y. (2008). Diseases of poultry. Iowa State University Press, Arnes.

Samour, J. (2015). Avian medicine. 3rd edition. Mosby Ltd.

Schmidt, R., Reavill, D., \& Phalen, D. (2015). Pathology of pet and aviary birds. Wiley-Blackwell.

Serdioucov, J. K., \& Zabudskyi, S. M. (2014). Zastosuvannya patomorfologichnikh doslidzhen' pri eksperimental'nij toksichnij dii kantaksantinu na organizm samok kol'orovikh kanarok [Application of research on experimental pathomorphological toxic effect of canthaxanthin on the organism of female coloured canaries]. Problemy Zooinzheneriji ta Veterynarnoji Medycyny, 28, 214-217 (in Ukrainian).

Serdioucov, J. K., Zabudskyi, S. M., Yacenko, I. V., \& Bogatko, N. M. (2015). Patomorfologiya toksikozu kantaksantinom u kol'orovikh kanarok [Pathomorphology of canthaxanthin toxicosis in coloured canaries ]. Problemy Zooinzheneriji ta Veterynarnoi Medycyny, 31, 262-265 (in Ukrainian).

Sobhakumari, A., Poppenga, R., \& Tawde, S. (2018). Avian toxicology. In: Veterinary toxicology: Basic and clinical principles. Third Edition. Pp. 711-731.

Sujak, A. (2009). Interactions between canthaxanthin and lipid membranes - possible mechanisms of canthaxanthin toxicity. Cellular and Molecular Biology Letters, 14, 395-410.

Surai, P. (2012). The antioxidant properties of cantaxanthin and potential effects in the poultry eggs and on embryonic development of the chick. World's Poultry Science Journal, 68, 465-476.

Walker, G. (1978). Coloured canaries by G. B. R. Walker. Blandford Press.

Zabudskyi, S. M. (2018). Zminy biokhimichnykh pokaznykiv krovi kanarok kol'orovykh za otruennya kantaksantinom [Changes in biochemical indicators of blood of coloured canaries poisoned with canthaxanthin]. Veterinariya, Tekhnologiji Tvarynnycztva ta Pryrodokorystuvannya, 2, 30-33 (in Ukrainian).

Zabudskyi, S. M. (2019). Zminy morfologichnykh pokaznykiv krovi kanarok kol'orovykh za otruennya kantaksantynom [Changes in morphological indicators of blood of coloured canaries poisoned with canthaxanthin]. Veterinariya, Tekhnologiji Tvarynnycztva ta Pryrodokorystuvannya, 3, 131-137 (in Ukrainian). 